\title{
Characterization of sporotrichosis cases treated in a dermatologic teaching unit in the State of São Paulo - Brazil, $2003-2013^{*}$
}

\author{
Gabriela Franco Marques ${ }^{1}$ \\ Juliana Martins Prazeres Sousa ${ }^{1}$ \\ Patrick Alexander Wachholz ${ }^{2}$
}

\author{
Ana Luiza Grizzo Peres Martins ${ }^{1}$ \\ Letícia Stella Gardini Brandão ${ }^{1}$ \\ Paula Yoshiko Masuda ${ }^{1}$
}

DOI: http://dx.doi.org/10.1590/abd1806-4841.20153447

\begin{abstract}
We conducted a transversal retrospective study with secondary data collection from 25 cases of sporotrichosis, treated at a teaching unit in inner São Paulo (Brazil), between the years 2003-2013. We found that the prevalence was higher in men (72\%), rural workers $(44 \%)$ and those living in rural areas $(60 \%)$, with an average age of 42.48 years. The median between the onset of lesions and diagnosis was six weeks. Lesions predominated in the upper limbs (92\%), and were classified as lymphocutaneous (80\%) and fixed cutaneous (20\%) forms. Clinical cure was observed in $62.5 \%$ of the cases treated with potassium iodide and $100 \%$ of cases treated with itraconazole.
\end{abstract}

Keywords: Epidemiology; Fungi; Mycoses; Sporotrichosis

Sporotrichosis is caused by dimorphic fungi belonging to the Sporothrix complex, being less severe and more common than other deep mycoses, with a subacute course and chronic evolution. ${ }^{1,2,3}$ It has a worldwide distribution, with reported cases predominating in countries of South and Central America, Africa, India and China. ${ }^{4,5}$

This study aims to evaluate the demographic, clinical and therapeutic features of patients with sporotrichosis assisted over a period of ten years, in a reference dermatology service located in the midwestern region of the state of São Paulo (Brazil).

This is a cross-sectional, retrospective, descriptive study with secondary data collection from medical records ranging from 2003 to 2013. We retrieved the multiprofessional charts of all patients with clinical diagnosis of sporotrichosis, as recorded in the archive of the institution's medical file system, according to the international classification of diseases (ICD-
10). Among them, only those cases with clinical diagnosis confirmed by microbiological examination (culture), with eventual support of histopathological assessment were included, comprising 25 patients.

Data from each patient were recorded on stardardized forms, independently reviewed by one of the authors, and transcribed to a Microsoft Excel ${ }^{\circledR}$ sheet. Descriptive statistics, through measures of central tendency for continuous variables and frequency distribution for categorical variables were used. Continuous variables with high variance and asymmetry according to the Kolmogorov-Smirnov (KS) test were presented as medians and quartiles.

As depicted in table 1, a predominance of sporotrichosis was identified in white $(80 \%)$, married $(60 \%)$, and male $(72 \%)$ patients, from the State of São Paulo (96\%), and those living in rural areas (60\%). The average age was 42.48 years $( \pm 21.35)$, ranging from 15 to 92 years.

\footnotetext{
Received on 13.02.2014.

Approved by the Advisory Board and accepted for publication on 27.02.2014.

Work performed at Instituto Lauro de Souza Lima (ILSL) - Bauru (SP), Brazil. Conflict of interest: None

Financial funding: None

Instituto Lauro de Souza Lima (ILSL) - Bauru (SP), Brazil.

Universidade Estadual Paulista "Júlio de Mesquita Filho" (UNESP) - Botucatu (SP), Brazil. 
TABLE 1: Demographic data of patients with sporotrichosis treated at a dermatologic teaching unit in São Paulo - Brazil, 2003-2013

\begin{tabular}{lll}
\hline Variables & Groups & $\mathbf{N}^{\mathbf{0}} \mathbf{( \% )}$ \\
\hline Gender & Masculine & $18(72 \%)$ \\
& Feminine & $7(28 \%)$ \\
Total & $\mathbf{2 5}(\mathbf{1 0 0} \%)$ \\
White & Black & $20(80 \%)$ \\
& Brown & $0(0 \%)$ \\
& Total & $5(20 \%)$ \\
Age & $<20$ & $\mathbf{2 5}(\mathbf{1 0 0} \%)$ \\
& $21-30$ & $2(8 \%)$ \\
& $31-40$ & $9(36 \%)$ \\
& $41-50$ & $1(4 \%)$ \\
& $51-60$ & $2(8 \%)$ \\
& $61-70$ & $5(20 \%)$ \\
Occupation & $>70$ & $5(20 \%)$ \\
& Total & $1(4 \%)$ \\
& Rural worker & $\mathbf{2 5}(\mathbf{1 0 0} \%)$ \\
& Maid & $11(44 \%)$ \\
& Veterinarian & $4(16 \%)$ \\
Origin & Other & $3(12 \%)$ \\
& Total & $7(28 \%)$ \\
& São Paulo & $\mathbf{2 5}(\mathbf{1 0 0} \%)$ \\
& Other States & $24(96 \%)$ \\
& Total & $1(4 \%)$ \\
& Metropolitan area & $\mathbf{2 5}(\mathbf{1 0 0} \%)$ \\
& Rural area & $10(40 \%)$ \\
& Total & $\mathbf{2 5 ( 1 0 0 \% )}$ \\
\hline
\end{tabular}

The most commonly reported occupations were rural worker $(44 \%)$, maid $(16 \%)$ and veterinarian $(12 \%)$. In clinical history reports, 10 patients $(40 \%)$ informed contact with sick animals, all of them cats. Eleven patients (44\%) reported previous local trauma, five scratches, one bite from a sick animal, and five cutting and/or piercing accidents with wood or plants. The time lapse between the appearance of the lesions and the diagnosis ranged from two to 48 weeks, with a median of six weeks, lower quartile of four and upper of 16 weeks.

Clinical characteristics are presented in table 2. Only two patients $(8 \%)$ reported co-morbidities, one had arterial hypertension and the other had polycythemia vera. All patients had the cutaneous clinical form, classified as fixed cutaneous (20\%) and lymphocutaneous $(80 \%)$ variants. Lesions were located predominantly in the upper limbs (92\%).

During the first consultation at the unit where this research was performed, 15 patients $(60 \%)$ reported having undergone prior treatment with oral or topical antibiotics, corticosteroids and topical antifungals. After the diagnosis, 21 patients initiated treatment and four were lost to follow-up. Among the treated patients, 14 received potassium iodide $3 \mathrm{~g} /$ daily and seven were medicated with itraconazole $200 \mathrm{mg} /$ daily, both drugs recommended for a twomonth use period.
TABLE 2: Clinical data obtained from patients with sporotrichosis seen at a dermatologic teaching unit in São Paulo - Brazil, 2003-2013

\begin{tabular}{|c|c|c|}
\hline Variables & Groups & $\mathrm{N}^{\mathrm{o}}(\%)$ \\
\hline \multirow{5}{*}{$\begin{array}{l}\text { Time in weeks between } \\
\text { the onset of lesions and } \\
\text { diagnosis }\end{array}$} & $<4$ & $4(16 \%)$ \\
\hline & $4-8$ & $9(36 \%)$ \\
\hline & $8-12$ & $3(12 \%)$ \\
\hline & $>12$ & $9(36 \%)$ \\
\hline & Total & $25(100 \%)$ \\
\hline \multirow{3}{*}{$\begin{array}{l}\text { History of contact with } \\
\text { a sick animal }\end{array}$} & Yes & $10(40 \%)$ \\
\hline & No & $15(60 \%)$ \\
\hline & Total & $25(100 \%)$ \\
\hline \multirow{3}{*}{$\begin{array}{l}\text { History of previous } \\
\text { local trauma }\end{array}$} & Yes & $11(44 \%)$ \\
\hline & No & $14(56 \%)$ \\
\hline & Total & $25(100 \%)$ \\
\hline \multirow[t]{3}{*}{ Co-morbidities } & Yes & $2(8 \%)$ \\
\hline & No & $23(92 \%)$ \\
\hline & Total & $25(100 \%)$ \\
\hline \multirow[t]{3}{*}{ Cutaneous form variant } & Lymphocutaneous & $20(80 \%)$ \\
\hline & Fixed cutaneous & $5(20 \%)$ \\
\hline & Total & $25(100 \%)$ \\
\hline \multirow{3}{*}{$\begin{array}{l}\text { Location of cutaneous } \\
\text { lesions }\end{array}$} & Upper limbs & $23(92 \%)$ \\
\hline & Other & $2(8 \%)$ \\
\hline & Total & $25(100 \%)$ \\
\hline \multirow[t]{4}{*}{ Culture } & Positivefor S. schenckii & $19(76 \%)$ \\
\hline & Negativefor S. schenckii & $4(16 \%)$ \\
\hline & Not performed & $2(8 \%)$ \\
\hline & Total & $25(100 \%)$ \\
\hline
\end{tabular}

Of all patients treated with potassium iodide, four reported adverse events such as abdominal pain, nausea and gustatory dysfunctions. Eight patients completed the treatment: five achieved clinical cure $(62.5 \%)$ and three did not respond to the medication $(37.5 \%)$; six patients dropped out of treatment. The three cases that did not respond to potassium iodide achieved clinical cure after two months of itraconazole $200 \mathrm{mg} /$ daily.

All patients treated with itraconazole attained clinical cure, without any reports of adverse events to medication.

Although we found a predominance of young men, similarly to the results of another survey, sporotrichosis affects people of both genders, in any age range or race, regardless of individual predisposing factors. ${ }^{1,4,5}$ The higher incidence observed among rural workers and professionals that are exposed to traumas caused by animals and plants denotes the occupational aspect of the disease. $2,5,6,7$

Sporotrichosis' clinical presentation is highly polymorphic: the most common clinical form is lymphocutaneous, followed by fixed and disseminated cutaneous presentations; the systemic form is quite rare ${ }^{7,8}$ Several factors such as host immunity, and the virulence of the inoculated strain, and the depth of 
traumatic inoculation may influence the different forms of presentation. ${ }^{1,4}$ Trauma-exposed areas emerged as the most affected ones, as previously described in the literature. ${ }^{6,7}$ The timeframe between the onset of lesions and the diagnosis was similar to that described in previous studies. ${ }^{5,8}$

Prognosis is mainly excellent when proper treatment is instituted. Despite reports of spontaneous healing, most cases demand pharmacological treatment. ${ }^{3}$ Choice of therapy depends upon the location and form of the disease. Potassium iodide, especially in endemic areas of developing countries, has been described as a more affordable and equally effective option in cutaneous forms, allowing imidazole derivatives to be used as first option or alternative drug for the treatment of localized cases. ${ }^{9,10}$ In disseminated cases or in patients with AIDS, amphotericin B is the drug of choice. ${ }^{3}$ Non-pharmacological therapeutic approaches, based on the application of thermotherapy by different methods have been described with varying success rates. ${ }^{3}$

Although not uncommon, sporotrichosis is a condition still frequently overlooked by population and by the public health system. The fact that this is not a disease with compulsory notification, that there are not laws to enforce the treatment of sick animals in cases of outbreaks, and the subacute clinical manifestations of the illness, all influences the patient to delay seeking for medical care. It is imperative, however, to recognize the clinical and epidemiological features of this disease and its appropriate treatment.

\title{
REFERENCES
}

1. Vásquez-del-Mercado E, Arenas R, Padilla-Desgarenes C. Sporotrichosis. Clin Dermatol. 2012;30:437-43.

2. Mata-Essayag S, Delgado A, Colella MT, Landaeta-Nezer ME, Rosello A, Perez de Salazar C, et al. Epidemiology of sporotrichosis in Venezuela. Int J Dermatol. 2013;52:974-80

3. Ramos-e-Silva M, Vasconcelos C, Carneiro S, Cestari T. Sporotrichosis. Clin Dermatol. 2007;25:181-7.

4. Barros MB, de Almeida Paes R, Schubach A0. Sporothrix schenckii and Sporotrichosis. Clin Microbiol Rev. 2011;24:633-54

5. Song Y, Li S-S, Zhong S-X, Liu Y-Y, Yao L, Huo S-S. Report of 457 sporotrichosis cases from Jilin province, northeast China, a serious endemic region. J Eur Acad Dermatol Venereol. 2013;27:313-8.

6. Takenaka M, Yoshizaki A, Utani A, Nishimoto K. A survey of 165 sporotrichosis cases examined in Nagasaki prefecture from 1951 to 2012. Mycoses. 2014:57:294-8.

7. da Rosa AC, Scroferneker ML, Vettorato R, Gervini RL, Vettorato G, Weber A. Epidemiology of sporotrichosis: a study of 304 cases in Brazil. J Am Acad Dermatol. 2005;52:451-9.

8. Sivagnanam S, Bannan AM, Chen SC, Ralph AP. Sporotrichosis (Sporothrix schenckii infection) in the New South Wales mid-north coast, 2000-2010. Med J Aust. 2012;196:588-90.

9. Yamada K, Zaitz C, Framil VM, Muramatu LH. Cutaneous sporotrichosis treatment with potassium iodide: a 24-year experience in São Paulo State, Brazil. Rev Inst Med Trop Sao Paulo. 2011;53:89-93.

10. de Lima Barros MB, Schubach A0, de Vasconcellos Carvalhaes de Oliveira R, Martins EB, Teixeira JL, Wanke B. Treatment of cutaneous sporotrichosis with itraconazole--study of 645 patients. Clin Infect Dis. 2011;52:e200-6.

\author{
MAILING ADDRESS: \\ Gabriela Franco Marques \\ Rua Alves Guimarães, $n^{\circ} 518$ Apto 136 \\ 05410-000 - São Paulo - SP \\ Brazil \\ E-mail: gabriela_franco_@hotmail.com
}

How to cite this article: Marques GF, Martins ALGP, Sousa JMP, Brandão LSG, Wachholz PA, Masuda PY. Characterization of sporotrichosis cases treated in a dermatologic teaching unit in the State of São Paulo - Brazil, 2003 - 2013. An Bras Dermatol. 2015;90(2):273-5. 